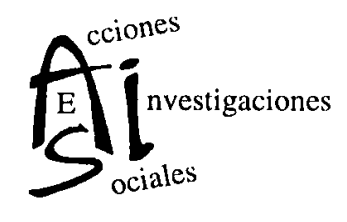

\title{
Exclusión de la población gitana en nuestra ciudad. Programa ACCEDER como acción de lucha contra la exclusión social de la población Gitana.
}

\author{
IsABel JimÉnez Cenizo \\ DIRECTORA TERRITORIAL EN ARAGÓN DE LA FUNDACIÓN \\ SECRETARIADO GENERAL GITANO
}




\section{Exclusión de la población gitana en nuestra ciudad. Programa ACCEDER como \\ acción de lucha contra la \\ exclusión social de la \\ población Gitana.}

Isabel Jiménez Cenizo

En la Comunidad Autónoma Aragonesa habitan cerca de 10.000 gitanos y gitanas la mayoría de ellos se encuentran en riesgo de exclusión social. El resto de población gitana aragonesa con recursos económicos suficientes, no está contabilizado en los Servicios Sociales de Base ni en otras entidades sociales por razones obvias.

En Zaragoza se concentra el $40 \%$ de esta población y a pesar de los avances que se han producido en el proceso de integración gitana en nuestra ciudad en las últimas décadas, es evidente que una buena parte de los gitanos y gitanas de nuestra ciudad, están muy por debajo de los niveles de vida medios de los ciudadanos zaragozanos, y que una serie de problemas les impide salir de su tradicional situación de exclusión.

En términos generales se puede hablar de varios tipos de situaciones en las que se encuentran los gitanos en nuestro municipio:

- Gitanos tradicionalmente integrados, de los que no se tiene constancia en los servicios sociales como ocurre con la mayor parte de la población y están dispersos en las distintas zonas de Zaragoza.

- Gitanos que han accedido a viviendas de altura en los últimos 15 años que se concentran en bloques de viviendas de algunos distritos de la ciudad.

- Gitanos que forman guetos por participar de la misma situación carencial a todos los niveles y son centro de permanentes conflictos vecinales y policiales como la zona de la Camisera en el barrio Oliver o en asentamientos se- 
gregados en furgonetas o chabolas, como El camino del Pilón, Camino del Vado...

- Gitanos que están llegando de países del Este o de Portugal en los últimos años y que representan una realidad cada vez más significativa y requiere un tratamiento específico.

\section{Necesidades de la población gitana en Zaragoza}

\section{Los principales problemas con los que se encuentran hoy buena parte de los gitanos en Zaragoza son:}

1. Un nivel de instrucción bajo, tanto en la población adulta como en la población infantil, debido a la asistencia discontinua a la escuela, a la falta de resultados de las instituciones educativas con este grupo de población, al abandono temprano y la escasa continuidad del proceso educativo una vez finalizada la etapa de la enseñanza obligatoria, que por otra parte en la mayoría de los casos tampoco se suele completar.

Si bien se ha conseguido una escolarización temprana y un acceso generalizado de la población infantil gitana a la escuela, existe todavía un alto índice de absentismo, sobre todo en los últimos cursos de primaria y en la ESO, un retraso escolar significativo y un abandono prematuro de la escolarización.

Además de estos aspectos, en general existen un déficit de atención a la diversidad cultural de estos niños y niñas que se concreta en la dificultad del profesorado tanto para realizar un seguimiento adecuado en las clases comunes. La escuela por tanto, no está siendo para la población infantil gitana un paso previo efectivo para la futura inserción laboral de estos niños y niñas, por lo que también se detectan dificultades en dar continuidad y ofrecer alternativas laborales a esta población.

Por otro lado, son muy pocos los gitanos que acceden a la oferta de formación profesional normalizada (Plan FIP, cursos del INEM,..), bien sea por falta de interés o bien por falta de adaptación de esos cursos a la situación, características y necesidades de los gitanos.

Actualmente en el plan FIP creemos que no hay más de un $3 \%$ de alumnos gitanos en Zaragoza. 
2. Pérdida generalizada de las profesiones y actividades laborales tradicionales en las que se habían ido especializando tradicionalmente (recogida de chatarra, cartón, temporerismo, etc.) y dificultad para seguir realizando las que ejercen actualmente (venta ambulante); profesiones que mayoritariamente se encuentran dentro de las economías informales y sumergidas y a las que hoy muchas de las familias no encuentran alternativas.

Profesiones ejercidas por cuenta propia actualmente en proceso de tranformación:

Venta ambulante, recogida de residuos sólidos y urbanos, temporerismo, es ejercido por un 50 y un $80 \%$ de la población activa gitana.

Profesiones liberales: Anticuarios, artistas entre un 5 y un $15 \%$.

Profesiones por cuenta ajena no cualificada, entre un 10 y un $15 \%$.

3. Situación degradada de la vivienda y el hábitat en algunos casos; chabolismo, asentamientos segregados, infravivienda, vivienda deteriorada y fuerte problema de hacinamiento para muchos de los que habitan en viviendas normalizadas, debido a la temprana edad de acceso al matrimonio, sus altas tasas de natalidad y su escasez de recursos económicos que obliga a la convivencia de varias familias en una misma vivienda.

4. Acceso y uso inadecuado (sea este por abusivo o escaso) de los servicios de carácter general de distinto tipo: sanitarios, sociales, de formación profesional, etc.

Se producen frecuentemente problemas de entendimiento con los profesionales de estos servicios, sentimientos de exclusión y de rechazo mutuos, etc.

De todos es sabido que los gitanos tienen dificultades en el acceso a los servicios públicos, especialmente a los sociales y a los educativos, sus peculiaridades culturales, su tradición sus referencias históricas, sus modos de vida, valores, expectativas, etc., hacen que en muchas ocasiones la relación entre gitanos y servicios y, quienes lo proveen, consideran que los gitanos no se adaptan y los instrumentalizan (Ej. acceso a las pensiones no contributivas).El nuevo modelo que se diseñe tiene que tener en cuenta el fracaso previo. 
5. Prejuicios, estereotipos y alto rechazo social hacia la población gitana en su conjunto (todos los estudios identifican a los gitanos como el grupo más rechazado socialmente) y relaciones interétnicas que frecuentemente son difíciles y conflictivas; especialmente en los barrios en los que habita un alto porcentaje de población gitana

Los prejuicios y estereotipos sociales inciden negativamente en la actitud de muchos ciudadanos que opinan que lo único que diferencia a los gitanos del resto de los ciudadanos es su retraso social o su situación de marginación.

Los medios de comunicación reproducen y alimentan en muchas ocasiones las imágenes y estereotipos negativos que pesan sobre la comunidad gitana como tal en su conjunto. $Y$ también las instituciones no son capaces de garantizar plenamente, en la aplicación cotidiana de la norma, la materialización y la proyección de los derechos de ciudadanía de los miembros de esta comunidad consagrados por la Constitución de 1978.

Incluso las propias políticas sociales, con vocación de favorecer la integración de este pueblo se hacen eco de este malentendido y, al no reconocer e incorporar el hecho de la diferencia cultural, acaban teniendo un efecto aislacionista.

\section{Fuerte proceso de transformación cultural}

Una serie de valores, normas y símbolos tradicionales se están transformando, esto, unido a la creciente diversificación entre el conjunto de la población, y el escaso conocimiento y valoración cultural por parte de la sociedad, pone en cuestión en muchas ocasiones la propia identidad de la comunidad gitana.

La calidad de vida de buena parte de la población gitana es muy inferior a la de la media de la población zaragozana.

Los gitanos, por lo general, viven menos años, padecen más enfermedades y más problemas de exclusión, lo que hace necesario que se pongan en marcha todos los medios y medidas específicas que sean necesarias, para que tengan la oportunidad de alcanzar la ciudadanía plena de acuerdo a los principios constitucionales. 


\section{Algunas propuestas operativas}

Las políticas sociales hacia la comunidad gitana, no pueden ser enfocadas exclusivamente desde el punto de vista de la exclusión social, sino que tienen que contemplar el hecho cultural diferencial y las consecuencias que implica el mismo.

Ignorar la diversidad de situaciones y actitudes del pueblo gitano así como olvidar el valor de un legado cultural incuestionable tras más de cinco siglos de convivencia, es también alimentar los planteamientos de "resistencia cultural" más desenfocados dentro de la comunidad gitana, y, en definitiva, aplazar indefinidamente la oportunidad de alcanzar un estadio social capaz de articular un intercambio cultural enriquecedor entre sus grupos.

La mayoría de los Estados siguen sin reconocer, en sus prácticas, el hecho diferencial gitano, a pesar de los avances que en este sentido se han producido a escala internacional, especialmente en las Convenciones, Recomendaciones y Resoluciones adoptadas por el Consejo de Europa.

Un ejemplo de ello es la atención que desde la política social europea, se está prestando hacia los gitanos como muestra su inclusión como grupo prioritario en alguno de los Programas Operativos del Fondo Social Europeo. En esta misma línea el Plan Nacional de Acción para la Inclusión Social, recoge expresamente medidas dirigidas a esta minoría.

En la Comunidad Autónoma Aragonesa, tiene que haber una política claramente definida de actuación con gitanos.

Para esto se propone:

- Que las principales Administraciones de nuestra Comunidad, Gobierno de Aragón y Ayuntamiento de Zaragoza, elaboren documentos orientadores en los que se incluyan las líneas de actuación y los criterios de intervención con esta población. Estos documentos tienen que servir de guía para los servicios públicos y privados que atienden a los gitanos en el municipio de Zaragoza y en el resto de municipios e instituciones.

- El documento debe ser elaborado por las administraciones y sometido a consulta de los distintos servicios municipales de la Comunidad Autónoma de Aragón, así como 
de las ONGs más activas en el trabajo con los gitanos y de las Organizaciones Gitanas

- Dicho documento que sería como un Plan de Actuación con gitanos en nuestra región, debe de orientar el conjunto de actuaciones y programas que se lleven a cabo, de manera que guarden coherencia y estén basados en los mismos criterios de actuación.

La actuación debe de dirigirse al conjunto de los gitanos que tienen necesidades y no sólo a los que habitan en vivienda de tipología especial.

Los gitanos que han pasado a una vivienda normalizada han dado el primer paso hacia la integración, pero eso no quiere decir que estén integrados. Si no hay un trabajo continuado de carácter integral, con los que ya han accedido a viviendas de altura, se corre el riesgo de que aumente la conflictividad social y que no se resuelvan muchos de sus problemas como la escolarización plena, uso correcto de vivienda, convivencia etc.

Cualquier actuación que se realice con la población gitana tiene que contar con el apoyo y participación de los propios gitanos y de las entidades que los representan.

Es imprescindible favorecer la participación de los gitanos en la toma de decisiones. Pero este es un proceso educativo lento que no se resuelve con la mera representatividad formal.

Es necesario contar con estructuras de mediación que movilicen a los gitanos y les acompañen en el acceso a los servicios, porque de lo contrario la experiencia demuestra que los utilizarán de modo incorrecto.

Especialmente en el seguimiento escolar, en la atención básica, en menores, en acceso al primer empleo, en acceso a viviendas de alquiler y compra. En algunos casos es necesario y aconsejable poner en marcha servicios específicos y adaptados a la población gitana, como único modo de garantizar la atención de la misma. En estos casos hay que clarificar muy bien cuales tienen que ser esos servicios y concebirlos siempre como de carácter transitorio y planificarlos de modo que sean integradores y no segregadores.

La actuación con gitanos tiene que combinar el enfoque social con el enfoque cultural.

El problema fundamental de los gitanos radica en su situación de pobreza y de exclusión social, pero su cultura (tradicio- 
nes, hábitos, modos de vida, referentes...), influyen también en esta situación. Por lo tanto ambas cuestiones deben de ser tratadas al unísono, siendo conscientes de que en la medida en que dotamos a las personas de condiciones para progresar socialmente, les damos la posibilidad de evolucionar culturalmente.

Es importante están especialmente atentos a este aspecto para evitar una política cultural que implante el mismo modelo que para otras minorías del país. Los gitanos tienen los mismos derechos que las otras minorías del país, pero dadas sus peculiaridades (falta de territorio de referencia, de historia escrita, de conciencia de pueblo en sentido político, etc.), es probable que el modo en que se garanticen esos derechos tenga que ser adaptado, o de lo contrario, en la práctica no se van a proteger y, además se caerá en efectos perversos.

Hay que diferenciar lo que son actuaciones promovidas desde los Servicios Sociales de la existencia de Políticas Sociales Integradas que incluyen otros ámbitos de desarrollo de la comunidad como son la vivienda, el acceso al empleo, la salud, la educación y la promoción cultural, entre otras. Todas ellas como parte de una intervención social integral son necesarias para abordar la realidad gitana en toda su complejidad.

Desde la Fundación Secretariado General Gitano, estamos incidiendo en Zaragoza y en Huesca, en el ámbito del empleo a través del Programa Operativo Pluriregional de Lucha contra la Discriminación (FSE 2000-2006) Programa de Acceso al Empleo ACCEDER.Acciones dirigidas a la población gitana.

Para el desarrollo del Programa ACCEDER, la FSGG, ha suscrito convenios de colaboración con los departamentos de la Administración autónoma y local responsables de las políticas de Bienestar Social y de Empleo, a través de las correspondientes concejalías, consejerías o institutos:

- Diputación General de Aragón: Instituto Aragonés de Empleo (INAEM) e Instituto Aragonés de Servicios Sociales (IASS).

- Ayuntamiento de Zaragoza;Concejalía de Cultura, Acción Social y Juventud.

- Ayuntamiento de Huesca, Fundación Municipal de Servicios Sociales. 
Las actuaciones que se desarrollan con la población gitana por medio del Programa ACCEDER, se sitúan en dos direcciones, interrelacionadas entre sí:

La primera de ellas es el impulso del acceso de la población gitana al empleo normalizado, con el compromiso de que, a la finalización

de la intervención del Programa Operativo en el periodo 2000-2006, unos 300 gitanos y gitanas en Aragón, hayan accedido a contratos de trabajo por cuenta ajena y alrededor de 1650 gitanos y gitanas de Zaragoza y Huesca, se hayan beneficiado de los servicios que desde nuestros dispositivos se desarrollan, mejorando sus condiciones de empleabilidad.

- La segunda línea de actuación es el impulso a la creación de servicios de proximidad orientados preferentemente a la mejora de la calidad de vida de las personas y, especialmente, a la integración social de la propia comunidad gitana. Estos servicios se impulsarán en el campo socio-educativo, socio-sanitario y socio-cultural.

Asimismo se pretende impulsar políticas socioculturales que sean más activas con población gitana y que en consecuencia abran nuevos espacios de formación y empleo en los que puedan participar los propios gitanos en tanto que educadores, mediadores, animadores, etc.

Los resultados que en este momento estamos teniendo son alentadores.

Hasta la fecha actual, diciembre de 2001, se han incorporado al Programa Acceder en Aragón un total de 1.016 usuarios y se han realizado $\mathbf{4 3 5}$ contratos de trabajo.

En Zaragoza, de 352 usuarios, 275 son de etnia gitana y 77 no son gitanos. Se han realizado 212 contrataciones, 145 han sido de personas gitanas y 67 no gitanas.

En Huesca, de 664 usuarios, 206 personas pertenecen a la población gitana y 461 a población inmigrante. De los 223 contratos realizados en esta ciudad, 94 contratos se han hecho a población gitana y 117 a inmigrante.

Total 239 personas gitanas han formalizado y cumplido con los contratos firmados en Aragón a lo largo del año 2001.

Nuestro reto en estos momentos es continuar con el crecimiento del Programa dando en cada situación la respuesta más idónea a nuestros usuarios. 
Probablemente se llegue a estabilizar el crecimiento del empleo y sea necesario implicarse con mas intensidad en la formación, en cualquier caso necesitaremos estar alerta para conseguir una mejor capacitación de los jóvenes que todavía no pueden acceder a los trabajos que exigen una mínima cualificación.

En cuanto a las políticas de empleo, culturales, sociales, somos conscientes de la necesidad de participar en los foros de debate y consulta necesarios para que el pueblo gitano tenga en ellos un espacio de interlocución y de reivindicación, además del reconocimiento de la cultura gitana, como una mas de las culturas que conforman nuestro país, desligándola, de una vez por todas, de la cultura de la marginación y la exclusión social. 